\title{
How can the digital library contribute to employability?
}

\author{
Karen Harbo*1 and Thomas Skov Jensen ${ }^{2}$ \\ ${ }^{1}$ Aarhus University Library, ${ }^{2}$ DTU Library
}

\begin{abstract}
The DEFF project, E-learning, Information literacy and Library services, supports the education policy ambition of enhancing links between education and employment. The project consortium includes libraries from all Danish universities, university colleges and one business academy. Timeframe for the project is 2014-16.
\end{abstract}

The project understands employability as:

In close cooperation with study programmes libraries will strengthen students' ability

to perform independently and critically in a professional context by being able to identify, collect, evaluate, organize and present information via digital platforms.

A partnership is made between the digital library (partner libraries involved) and the virtual learning environment (educational institutions), based on the above definition of employability. This is done within the framework of Learning Management Systems (LMS) and Massive Open Online Courses (MOOCs). The libraries and academic programmes will collaborate to create elearning objects based on the relevant digital library systems and information resources.

Departments from three Danish universities will contribute by strengthening the project participants' skills in e-didactics and the development of e-learning objects (SDUUP, University of Southern Denmark), developing a range of flexible concepts for the integration of the virtual library into learning environments (IVA, Copenhagen University) and evaluating the project's activities (E-Learning Lab, Aalborg University).

Sustainable results include the training of library staff to work together with academic programmes via the virtual learning environments, the development of flexible concepts for integrating the virtual library with study environments and knowledge on how inputs, created by the project for each study programme, should function.

\author{
*Contact: \\ Karen Harbo \\ Aarhus University Library, Denmark \\ E-mail: har@au.dk
}




\section{Introduction}

In November 2013, a significant number of Danish educational libraries asked themselves the question, how libraries could enhance students' employability? The issue, now formulated in a broader context, was taken on in a project application to Denmark's Electronic Research

Library (DEFF) entitled E-learning, Information Literacy and Library Service - how can the digital library contribute to employability? DEFF allotted funds for the submitted application and the project has been working intensively on this topic during the 2014-2016 period.

The project consortium wanted to test traditional library teaching in information literacy, in relation to new developments in education. Firstly, the increasing digitization of educational institutions in Denmark, including the general implementation of second generation Learning Management Systems (LMS), Massive Open Online Courses (MOOCs) and new ways of learning (e-didactics). Secondly, the ambition of the libraries to follow and support the Danish education policy ambition of enhancing links between education and employment. By doing so, the project encountered and tried to respond to new challenges to libraries' efforts in the area of information literacy.

A broad, collaborative project consortium drove the project forward:

- Aarhus University Library (financial and legal owner, and the manager of the project)

- Aalborg University Library

- DTU Library, Technical Information Center of Denmark

- Copenhagen Business School Library

- Copenhagen University Library

- Roskilde University Library

- University of Southern Denmark Library

- VIA University College Libraries on behalf of all university college libraries in Denmark

- KEA, Copenhagen School of Design and Technology

- An Advisory Board of educational institution representatives followed and advised on the project.

The goals set by the project consortium was to investigate how the digital library can create value and stimulate development in education and virtual learning environments, and how libraries can help support students' digital development and learning by giving them access to qualified information and by providing them with e-based tools and methods for the handling of complex information issues. Tools and methods that should continue to be of advantage to them when they enter the labour market.

As the subject employability was central to the project, it was important for the project consortium that all parties endorsed a common understanding of libraries' contributions to increasing the employability of students.

The project consortium endorsed this pragmatic definition:

The ability to act independently and critically in a professional context by being able to identify, collect, evaluate, organize and present information in and on digital platforms.

The definition builds on traditions and literature within the field of information literacy.

Academic libraries have, over time, tended to develop their support for student's ability to manage information in connection with the acquisition of academic skills based on a combination of theory and practice. Thus, this project, given the above mentioned definition is 
grounded in SCONUL's seven pillars of information literacy: to identify, scope, plan, gather, evaluate, manage and present information (SCONUL Seven Pillars of Information Literary, 2011). All of which form the information literacy landscape, 'the information literate person'. The project added an additional - eighth - parameter: to be able to reflect on the practice of information literacy in an academic professional context. Furthermore, the project assumed activity in a virtual environment - in and on digital platforms.

The project functioned as a matrix organization. The national level involved all parties, and all joint activities and the general sharing of knowledge took place there. The local level involved the nine individual libraries, in collaboration with academic staff at the respective educational institutions, seeking to develop library-oriented e-learning objects, which could support students' employability.

\section{Methods}

Overall methods

In order to achieve the goals set, the project chose the following methods:

- Collaboration on specific academic programmes by integrating information and relevant library services in the form of e-learning objects which are targeted at courses under these programmes

- Close cooperation with course lecturers concerning the content of e-learning objects

- Presence of e-learning objects in the respective virtual learning environments: Learning Management Systems (LMS) and Massive Open Online Courses (MOOCs)

- Continuity through additional programs during the implementation phase (from 2015 to 2016) - to ensure sustainability of results

- Strengthening the project participant's skills in e-didactics and the development of elearning objects based on digital library systems, resources and services

- Devising common flexible concepts for integration of the digital library in educational environments. Concepts that can be reused or adapted by colleagues from a broad variety of library and educational environments

- Conducting evaluations of the implemented programmes, which, on a systematic basis, will document not if, but how, the virtual library creates value for the employability of the students.

\section{Competence development}

In order to strengthen the project participant's skills in e-didactics and their ability to produce elearning objects, the project had to look for external inspiration. A competence development programme (5 workshops +1 online course) was arranged for the project group (October 2014 March 2015) and carried out by Senior E-learning Advisor, Inger-Marie Christensen, University of Southern Denmark, SDU Centre for Teaching and Learning. Titles of the individual modules in the program are shown below, all of which library staff need to be familiar with when teaching students in the virtual classroom of the future.

- Introduction, design of blended learning / e-didactics

- Design, production and publishing of e-learning objects and e-tutorials

- Interactivity and e-learning objects

- Rubrics, self- and peer evaluation

- Series of online workshops: Live online communication and support - Live online teachers

- New ways of engaging and motivating the students 
Flexible concepts for integrating the digital library into educational learning environments In order to devise common flexible concepts for integration of the digital library in educational learning environments we too needed external inspiration. Lector, Trine Schreiber, The Royal School of Library and Information Science, Copenhagen University handled this task by conducting several in depth interviews with the project participants, concerning the actual elearning courses and e-learning objects developed. The interviews led to a report now available (in Danish) based on the consolidation and analysis of the qualitative data obtained.

Across the eleven projects, nine concepts have been found. Each concept is not based on any one individual project. Instead, they draw on content from elements of all projects. In this way, the presentations of the concepts are based on examples taken from the projects. The selection of examples is, however, inspired by e-learning theory concepts and models such as the e-didactic model. The aforementioned model, for example, has entered into discussions both within as well as across the local projects.

The different concepts should not be seen as strictly separate from each other. Several of them can be usefully combined with each other. [Translated and authors' highlight] (Schreiber, 2015).

The nine flexible concepts [translated]:

1. Teacher as co-producer concept

2. Student as co-producer concept

3. Peer assessment concept

4. Teaching loop concept

5. Gamification concept

6. Flipped classroom concept

7. Shortcuts concept

8. Case concept

9. Open learning resources concept

\section{Evaluation of how the digital library creates value}

With the purpose of conducting evaluations of how the digital library creates value for the employability of the students the project engaged an external partner, Professor Marianne Lykke, E-Learning Lab, Aalborg University. The survey design comprised two parts. Firstly, a general quantitative survey, covering all courses with which the local projects have collaborated, was implemented. Secondly, a special qualitative part concerning four specific courses was implemented by focus group interview.

A preliminary look at the data tells us that the project's e-learning objects score highly among the students with respect to information and reliability - but leaves something to be desired on the creative and curiosity arousing side.

A report from E-Learning Lab, Aalborg University is available by the end of August 2016.

\section{Integration and collaboration}

The many local projects have worked closely together with the different academic programmes to ensure that the library is not just an 'add on' to the education taking place, but fully integrated into the curriculum. 
Based on talks, meetings, interviews, observations, surveys, and reviews of the course material and the curriculum, the local projects were actively engaged in delivering content to the respective academic programmes and in some cases librarians were even asked to take on the challenge of designing the course site.

The librarians have primarily been working together with the lecturers, but in other cases the dialogue has been between a director of studies, a coordinator of semester, a network of educational services or even the students themselves.

The collaboration between the libraries and the academic programmes are in many cases a result of contacts and networks that were established well before this project ever became a reality.

Most of the lecturers the local projects collaborated with are facing the same challenges as the libraries regarding how best to implement and contribute to the virtual learning environments. Thus the initiatives, which were taken by the librarians in this project, were most often received in a positive spirit by the lecturers, because they saw this as a great opportunity to further develop and strengthen the e-learning elements of their own courses.

The integration of the library-based input to the different courses has been carried out in various ways. Sometimes the e-learning objects created by the libraries have been implemented in the curriculum; sometimes lecturers have presented and then encouraged or even demanded that students actively apply the e-learning objects, created by the libraries, to their studies. In other instances, the librarians have even been offered the opportunity to present the e-learning objects to the students themselves. Thus, they have been given, not only the chance to explain the purpose of the e-learning object in their own words, and last but not least, it has given the libraries a window of opportunity for getting invaluable feedback from the students.

\section{E-didactics - developing and applying new competencies}

As mentioned earlier, the integration of library-based input to academic programmes and the collaboration between lecturers and librarians have been situated in a number of flexible concepts (Schreiber, 2015). However, it is important to underline that the use of these concepts has been carried out in a non-exclusive manner. This means that the librarians have often combined a number of the different concepts in their respective local projects.

One example of this can be found in the local project created by the VIA University College Libraries, where the case concept was combined with the student as co-producer concept. Another example of mixing concepts is found in the MOOC part of the project that combined peer assessment and flipped classroom in the local application of the MOOC.

The application of these concepts is based on emerging e-learning theory and most prominently by a model of e-didactical design. This model, which was presented to the project within the joint competence development programme, deals with the development, design and implementation of e-learning by addressing 8 different parameters essential to this process:

- Learning objectives

- Learning activities

- Technologies

- Evaluation

- Time

- The roles of the lecturers

- The roles of the students

- Space

(Pedersen \& Bertelsen, 2015 ; "Det digitale lærerteam - Design", 2012) 
Furthermore, the competence development programme introduced the concept of e-tivities based on the work done by Gilly Salmon (Salmon, 2013). The concept of e-tivities is based on the notion that learning activities created in an online environment hold potentials and constraints that on some levels differ from learning activities in a physical environment.

The model of e-didactical design and the concept of e-tivities provided the project with a context in which the local projects were able to inspire each other. They also learned more about the not so tangible, and in fact rather difficult, challenge of how best to design and develop elearning objects capable of supporting students' information literacy and at the same time enhancing their employability.

Alongside these workshops, the local projects began to produce a variety of e-learning objects: videos, quizzes, games, rubrics, assignments, tutorials, tests, libguides, virtual Q\&A sessions, webinars etc. These were all created with the purpose of being integrated in the specific academic programmes that the local projects have made contact with, while at the same time taking into account within which specific LMS or MOOC platform they were meant to be used.

The LMS's and MOOC platforms relevant to this project were:

- Moodle

- Blackboard

- Learn

- Fronter

- CampusNet

- Coursera (MOOC)

Local projects - local networking

Partly on the basis of what we had learned in the joint competence development programme about e-learning and e-didactics and partly because of the shared knowledge of ideas and a priori practices, the local projects went on to involve various strategic partners from their own local contexts.

The competences that were in demand by the local projects were within the following categories:

- IT

- E-Didactical/E-Pedagogical

- Communication/Design

Almost all the local projects needed partners that would be able to support the process in terms of handling the practical and technical issues associated with the production of the various e-learning objects. Furthermore, the library staff also received support that helped solve technical challenges connected to the different LMS and thus have contributed in qualifying and enhancing the technical solution that our e-learning object depended on.

The e-didactical and e-pedagogical skills and competences were also in high demand throughout the project. Partners that would be able to qualify the pedagogical and e-didactical strength of the respective e-learning objects were addressed.

A third set of competences that was sought by the local projects were partners that would be capable of helping the library staff create their videos, quizzes, games, tutorials, etc. according to local design manuals and marketing standards. 
Last but no less important were the competences that the local projects failed to find in side their local organisation. An example of this was the competences needed in a local project that wanted to create an e-learning object in the form of a game. In this case no obvious local partner was available to the librarians and thus they required the support and competences of an external consultant.

The librarians forming strategic partnerships inside, and in a few cases outside, their parent organisation have strengthened and qualified the e-learning products considerably, and it has formed valuable networks and contacts for the librarians personally and for the libraries in general. These are contacts and networks that the library staff and the libraries will need to explore and build on in the years ahead.

\section{Sustainable results}

Learninglib.dk - a shared knowledge-sharing platform of e-learning objects

Learninglib.dk is an already existing platform for library produced e-learning objects in Denmark, developed earlier within the framework of a successful DEFF project. The project $E$ Learning, Information Literacy and Library Services undertook further development of this platform as an archive of the many and varied e-learning objects, which are actual outputs of the project, agreed to be shared via Creative Commons. As such, Learninglib.dk has even more potential to become the knowledge-sharing platform of the e-learning objects produced by Danish academic and educational libraries in the future.

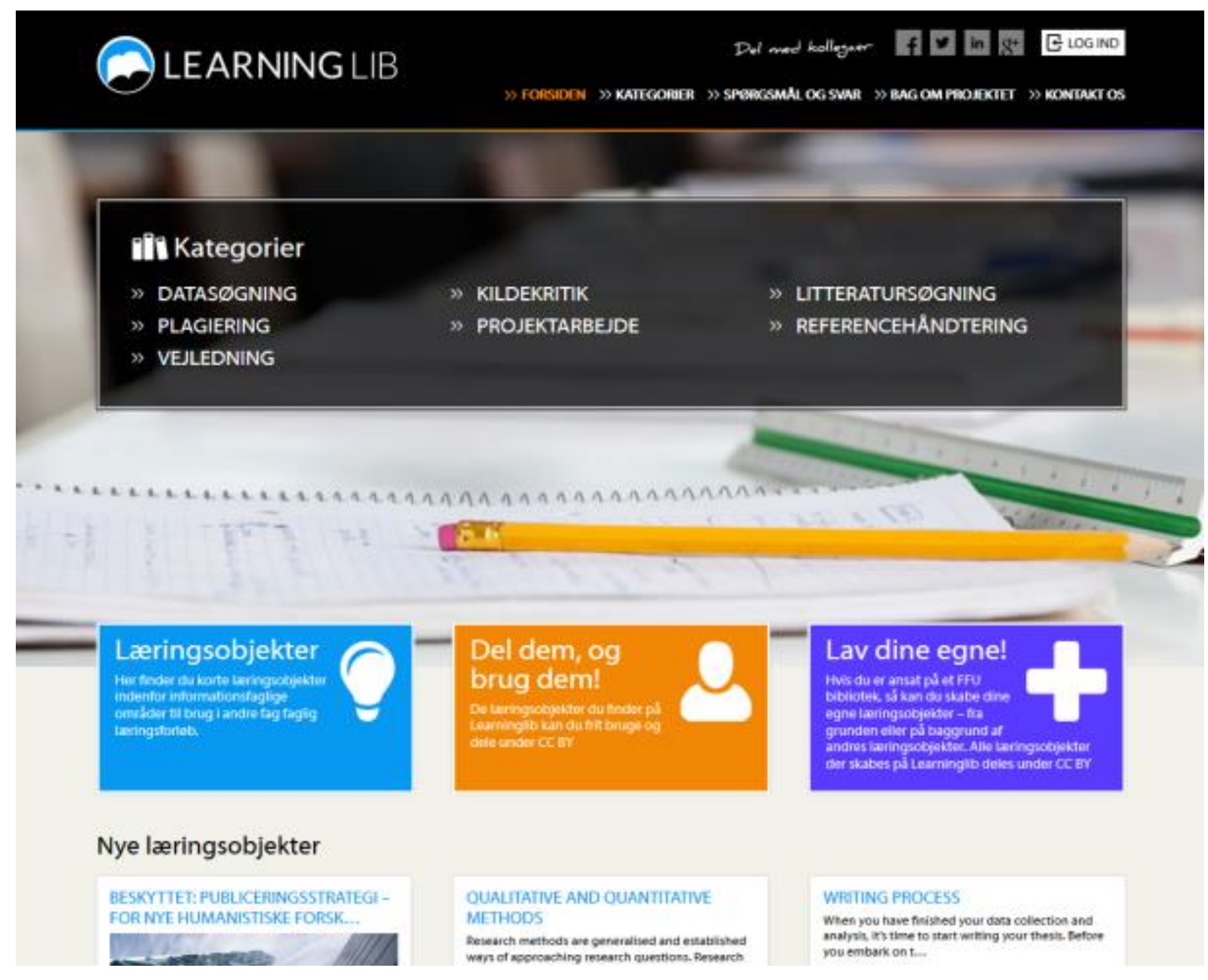


The world's first MOOC about academic information seeking

One of the local projects was the development and production of a MOOC on the Coursera platform. The MOOC Academic Information Seeking consists of three modules, which aim to support students taking on the task of writing a report, an assignment or a thesis.

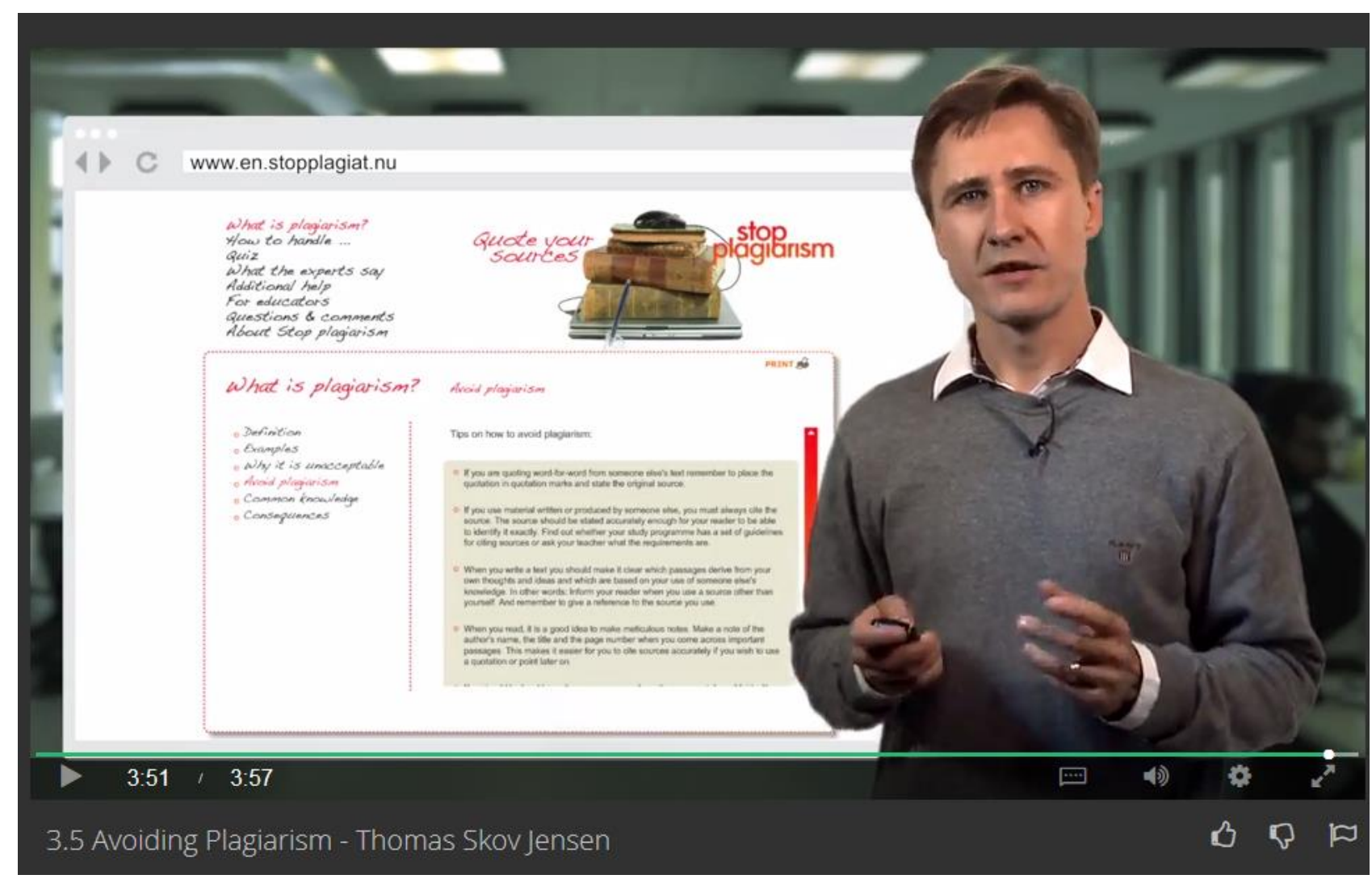

The first module is concerned with the preparation of the information seeking process, the second module addresses the process of actually performing information searches, while the third module takes a closer look at how to use and evaluate the results.

Unlike the local projects dedicated to creating one or more individual e-learning objects for the various LMS platforms, the MOOC part of the project focused on delivering a complete course aimed at a global audience.

The MOOC was launched at the start of December 2015 and by the start of August 2016 numbers show that:

- 10834 have visited the course

- 4917 have enrolled in the course

- 2646 have been active in the course

- 272 have completed the course

- 46 have payed $49 \$$ for the course and

- there are people from 151 different countries represented in the course

The MOOC part of the project has in a lot of different ways been acting a little differently compared to the local LMS projects. However, some of the key issues highlighted in the experience of producing and delivering the MOOC can also be seen in the LMS counter parts. 


\section{New ways of working}

The project participants have introduced new ways of working within the area of information literacy. This was done by completing the competence development programme, by familiarizing themselves with the new flexible concepts for integration of the digital library in educational learning environments, and by practicing this new learning in the local projects. The ongoing sharing of knowledge that took place among the project participants and the collaboration with the respective academic, and other local partners, has also been an inspiration. Furthermore, the networking sheds light on the branding of the libraries of the consortium and their capability of adding value to the academic programmes. The evaluation report will complement these developments, identify knowledge of how e-learning objects have enhanced students' employability and highlight ways in which we can develop further.

\section{Conclusion}

The project has produced a range of e-learning objects targeted at specific academic programmes based on digital library systems, resources and services. This was done in close collaboration with lecturers. The e-learning objects were presented at the various virtual learning environments of Danish educational institutions, and will now be shared via Creative Commons on the knowledge-sharing platform of e-learning objects, produced by Danish academic and educational libraries, Learninglib.dk.

The MOOCs constitute a brand new arena for the libraries and the librarians, but it is nevertheless an arena we need to familiarize ourselves with, since the educational systems that we support seem to be giving it more and more attention. MOOC production gives rise to new insights, skills, and e-learning objects that can be applied in all the different settings in which we as librarians support students' information literacy and their subsequent employability.

The project participants learned new methods and ways of working by participating in the competence development programme and by being interview-partners in the process of devising the flexible concepts for integration of the digital library in educational learning environments. They also learned by trying out these methods and concepts in the practice of the local projects. Furthermore, the networking, both with the partners of the national project and with the partners at the local educational institutions, has been an inspiration for future ways of working within the area of information literacy.

A conference, Collaboration between Libraries and Education - towards 2020, on the $9^{\text {th }}$ of November 2016, at Moesgaard Museum, Aarhus, will close the project by focusing on strategic considerations for libraries' work with e-learning and information literacy, which can match future trends in the field of educational-IT. One of the main conclusions of the project emphasizes the fact that the libraries of the project consortium in collaboration with the educational institutions involved must continue working on the project results and learning in the future. 


\section{References}

Academic Information Seeking, (2015). Retieved from

https://www.coursera.org/learn/academicinfoseek

Det digitale lærerteam - Design. (2012). Retrieved from https://rhachmann.wordpress.com/2012/04/25/det-digitale-laererteam-design/

Pedersen, L., \& Bertelsen, J. V. (2015). Håndbog i brug af Blended Learning i UCL. Pre-print version. Retieved from

https://www.ucviden.dk/portal/en/publications/haandbog-i-brug-af-blended-learning-iucl(a1279bda-7114-4434-a010-66e7c7d142bc).html

Salmon, G. (2013). E-tivities : the key to active online learning. Routledge.

Schreiber, T. (2015). Fleksible koncepter for integration af det virtuelle bibliotek i uddannelsernes læringsmiljøer. [Flexible concepts for integrating the virtual library into educational learning environments]. Retrieved from

http://www.deff.dk/nyheder/ni-fleksible-koncepter-til-integrationen-af-e-biblioteket-ilaeringsmiljoeerne/

The SCONUL Seven Pillars of Information Literacy. (2011). Retrieved from http://www.sconul.ac.uk/sites/default/files/documents/coremodel.pdf 